\title{
TRANSIÇÃO DEMOGRÁFICA NO BRASIL: UM ESTUDO SOBRE O IMPACTO DO ENVELHE- CIMENTO POPULACIONAL NA PREVIDÊNCIA SOCIAL. ${ }^{1}$
}

\section{DEMOGRAPHIC CHANGE IN BRAZIL: A STUDY ON THE IMPACT OF AGING POPULATION ON SOCIAL SECURITY}

\author{
Michelly Vieira do Nascimento \\ Mestranda em Demografia pela Universidade Federal do Rio Grande do Norte. \\ michelly0508@hotmail.com \\ Victor Hugo Dias Diógenes \\ Doutorando em Demografia pela Universidade Federal do Rio Grande do Norte. \\ Universidade Federal da Paraíba. \\ victordiogenes@gmail.com
}

\begin{abstract}
RESUMO
Objetivo: Mostrar o impacto do envelhecimento populacional sobre os gastos com benefícios concedidos do RGPS.

Fundamento: A transição demográfica trata-se de uma mudança no comportamento da mortalidade e fecundidade de um país, o que provoca alguns efeitos, principalmente na estrutura etária, gerando o envelhecimento populacional. Estima-se que a população brasileira começou a passar por esse processo por volta de 1970, quando a fecundidade começou a decrescer em conjunto com a mortalidade. A nova estrutura envelhecida traz desafios para as políticas públicas do país, principalmente à previdência social organizada pelo regime geral (RGPS), que terá que se adaptar de acordo com a nova massa de seus beneficiários e contribuintes.
\end{abstract}

Método: Foi utilizada uma técnica demográfica conhecida como padronização direta, que possibilitou estimar uma taxa bruta de consumo em gastos previdenciários em uma população jovem (brasileira) e em uma população envelhecida (italiana), com a finalidade de compará-las e analisar como se dará o comportamento dos gastos previdenciários em uma população com uma estrutura etária idosa, como a esperada que o Brasil vivencie por volta de 2050.

Resultados: Como resultado observou-se um aumento dos gastos previdenciários com a população total, em especial quando analisado por sexo, com uma elevação nos benefícios concedidos aos homens.

Contribuições: $\mathrm{O}$ artigo colabora para a discussão sobre os efeitos das mudanças demográficas ocorridas na população do Brasil sobre o Regime geral de previdência social (RGPS), dado que a partir do encontrado verifica-se um aumento dos dispêndios com benefício decorrente apenas do envelhecimento populacional, frente a uma redução da população contribuinte no longo prazo.

\footnotetext{
${ }^{1}$ Artigo recebido em: 18/04/2019. Revisado por pares em: 13/08/2019. Reformulado em: 12/09/2019. Recomendado para publicação: 23/11/2019 por Luiz Felipe de Araújo Pontes Girão (Editor Adjunto). Publicado em: 01/05/2020. Organização responsável pelo periódico: UFPB
} 
Desse modo, esse trabalho contribui com a literatura sobre o assunto ao conseguir identificar e mensurar o impacto isolado do envelhecimento populacional no equilíbrio financeiro do RGPS.

Palavras-chave: Transição demográfica. Envelhecimento populacional. Previdência social. Gastos previdenciários.

\begin{abstract}
Objective: Show the impact of population aging on the expenses with benefits granted by the RGPS.

Background: The demographic transition is a change in the behavior of mortality and fertility of a country, which causes some effects mainly on the age structure, leading to population aging. It is estimated that the Brazilian population began to go through this process around 1970, when fertility began to decrease together in mortality. The new aging structure brings challenges to the country's public policies, especially the social security organized by the general regime (RGPS) that will have to adapt according to the new mass of its beneficiaries and contributors.

Method: For this, a demographic technique known as direct standardization was used, which made it possible to estimate a gross rate of consumption in social security spending in a young (Brazilian) and an aged (Italian) population, with the purpose of comparing them and analyzing how they are used the behavior of social security spending in a population with an older age structure, such as Brazil's expected to experience around 2050

Results: As a result there was an increase in social security spending with the total population, especially when analyzed by gender, with a rise in benefits granted to men.

Contributions: The paper contributes to the discussion on the effects of demographic changes that occurred in the population of Brazil on the General Social Security System (RGPS), based on the findings that there is an increase in expenditures with a benefit resulting only from population aging, compared to a reduction in the contributing population in the long term. Thus, this paper contributes to the literature on the subject by being able to identify and measure the isolated impact of population aging on the financial balance of the RGPS.
\end{abstract}

Keywords: Demographic transition. Population-ageing. Social Security. Social security expenditures.

\title{
1 INTRODUÇÃO
}

Por volta da metade do século XX, o Brasil começou a vivenciar uma mudança nos seus regimes demográficos, que consiste na saída de altos para baixos níveis de mortalidade e fecundidade. Como principais consequências deste fenômeno tem-se o processo de aumento da longevidade e do envelhecimento populacional, que consiste no aumento da participação proporcional da população idosa e diminuição das taxas de crescimento populacional (Carvalho \& Wong, 2006; Vasconcelos \& Gomes, 2012).

Toda a sociedade está sujeita a enfrentar grandes desafios decorrentes deste processo, conhecido como transição demográfica. Por haver uma mudança na estrutura etária da população, as políticas públicas que antes eram voltadas para uma população jovem, terão que se adaptar para suprir as necessidades de uma população envelhecida. Caso isto não aconteça, a eficiência destas políticas ficará comprometida (Brito, 2007; Caetano et al., 2016).

Dentre estas, a previdência social organizada pelo regime geral (RGPS) será uma das políticas mais afetadas com o processo da transição demográfica, por se basear no regime financeiro de repartição simples, e terá que se adaptar a esta nova estrutura etária da população. Segundo Tafner (2012), as mudanças demográficas estão na raiz dos desequilíbrios estruturais dos sistemas previ- 
denciários constituídos sob o princípio de repartição simples, isso porque, nesse sistema, a geração ativa financia os benefícios da geração inativa. Assim, uma geração numerosa de inativos exigirá uma geração numerosa de ativos ou se for inferior, que os ganhos de produtividade desta sejam elevados o suficiente para conseguir arcar com essa contraprestação. A classe dos ativos compreende em sua maioria a população em idade ativa (PIA), por isso a magnitude deles é tão importante para garantir o funcionamento da previdência.

Segundo dados do Instituto Brasileiro de Geografia e Estatística [IBGE] de 2013, a população de jovens (0-14 anos) sofrerá uma redução de 15,97\% entre 2000 e 2050, enquanto a de idosos no mesmo período aumentará $17,04 \%$, e a PIA (15-64 anos) sofrerá um decréscimo de 1,07\%. Apesar de a projeção indicar uma pequena redução da PIA, alerta-se que o fato mais desconcertante para a previdência é que haverá um aumento constante da parcela da população idosa em relação à população total brasileira, provocando impactos nas formulações de políticas públicas e no equilíbrio fiscal do país. Desse modo, este trabalho visa informar os motivos desse efeito demográfico e suas consequências especificamente na previdência social.

A transição demográfica ocorre na maioria dos países, mas em velocidades diferentes (Tafner, Botelho, \& Erbisti, 2014). Países da Europa como a Alemanha, Itália e Grécia já enfrentam o cenário em que o Brasil se encontrará em 2050, de acordo com projeções do IBGE de 2013, quando a população idosa será maior do que a população jovem. A Alemanha, em 2016, apresentou a proporção da população jovem de $13,9 \%$ em relação à população total, enquanto a população idosa representava $21,27 \%$, o mesmo ocorreu na Grécia, com a população jovem de $14,35 \%$ e a idosa 20,19\%, e na Itália com 13,61\% de jovens e 22,71\% de idosos (Banco Mundial, 2018). Nesta fase, as taxas de crescimento populacional se encontram próximas de zero e até negativas, como nos casos da Alemanha (0,81\%), Grécia (-0,42\%) e Itália (-0,17\%) em 2016, segundo dados do Banco Mundial (2018).

Destarte, dado que o processo da transição demográfica, especificamente no que tange ao envelhecimento da população, é um processo consolidado e muito provavelmente irreversível, e que a previdência social brasileira é baseada no regime de repartição simples, cuja maior característica é justamente a dependência intergeracional, cabe o seguinte questionamento: "qual é o impacto do envelhecimento populacional nos gastos da previdência social baseada no regime geral de previdência social?".

O objetivo desta pesquisa, portanto, é identificar o impacto do envelhecimento da população brasileira nos gastos com benefícios da previdência social organizada pelo regime geral. Para alcançar tal objetivo foi apresentada a evolução da transição demográfica brasileira, buscando evidenciar a mudança na estrutura etária da população, e como este cenário influencia os gastos com os benefícios previdenciários, assim foram estimadas essas despesas utilizando a estrutura etária de uma população mais envelhecida.

É ampla a literatura que discorre o envelhecimento populacional e os desafios impostos à Previdência Social neste novo contexto demográfico. No entanto, em menor quantidade, são os estudos que operacionalizam e quantificam o efeito de uma população mais envelhecida no sistema público de previdência (Giambiagi \& Tafner, 2010; Costanzi \& Ansiliero, 2017). Desse modo, o esforço de uma proposição metodológica sobre esse tema se caracteriza como uma potencial contribuição para a literatura sobre o tema.

\section{REFERENCIAL TEÓRICO}

\subsection{Transição Demográfica no Brasil}

Depois da segunda guerra mundial, avanços na medicina, melhorias do saneamento básico e na saúde pública melhoraram as condições de vida da população, e como consequência, as taxas de mortalidade foram diminuindo, principalmente em relação às crianças, ocasionando um au- 
mento da expectativa de vida (Bloom,Canning, \& Sevilla, 2003, tradução nossa). Dar-se então o início da primeira fase da transição demográfica, onde as taxas de mortalidade decrescem e a de fecundidade permanece em alta, provocando assim, um aumento expressivo da população. De acordo com Carvalho e Wong (2008), este decréscimo na mortalidade foi observado no Brasil de forma mais intensa entre os anos 1940 e 1960 (Gráfico 01), o que gerou um aumento da população jovem brasileira (0-14 anos).

No entanto, por volta de 1970, a taxa de fecundidade começou a decrescer, como pode ser visto no Gráfico 02, acarretando um aumento proporcional da população em idade ativa (15 - 64 anos). Porém, em torno do ano 2000 o Brasil começou a enfrentar outro cenário, como consequência da desaceleração do crescimento populacional brasileiro (decorrente da diminuição da taxa de fecundidade). O número de jovens começou a decrescer e o de idosos a crescer, assim houve uma mudança na estrutura etária da população brasileira. Para Alves, Vasconcelos e Carvalho (2010), a estrutura etária de um país muda ao longo do tempo, acompanhando as mudanças decorrentes da transição demográfica, e no caso do Brasil, que já enfrenta uma fase mais acentuada da transição, deve-se apresentar ainda significativas mudanças na estrutura etária da sua população nas próximas décadas.

GRÁFICO 01- Taxa de mortalidade do Brasil de 1900 a 2016

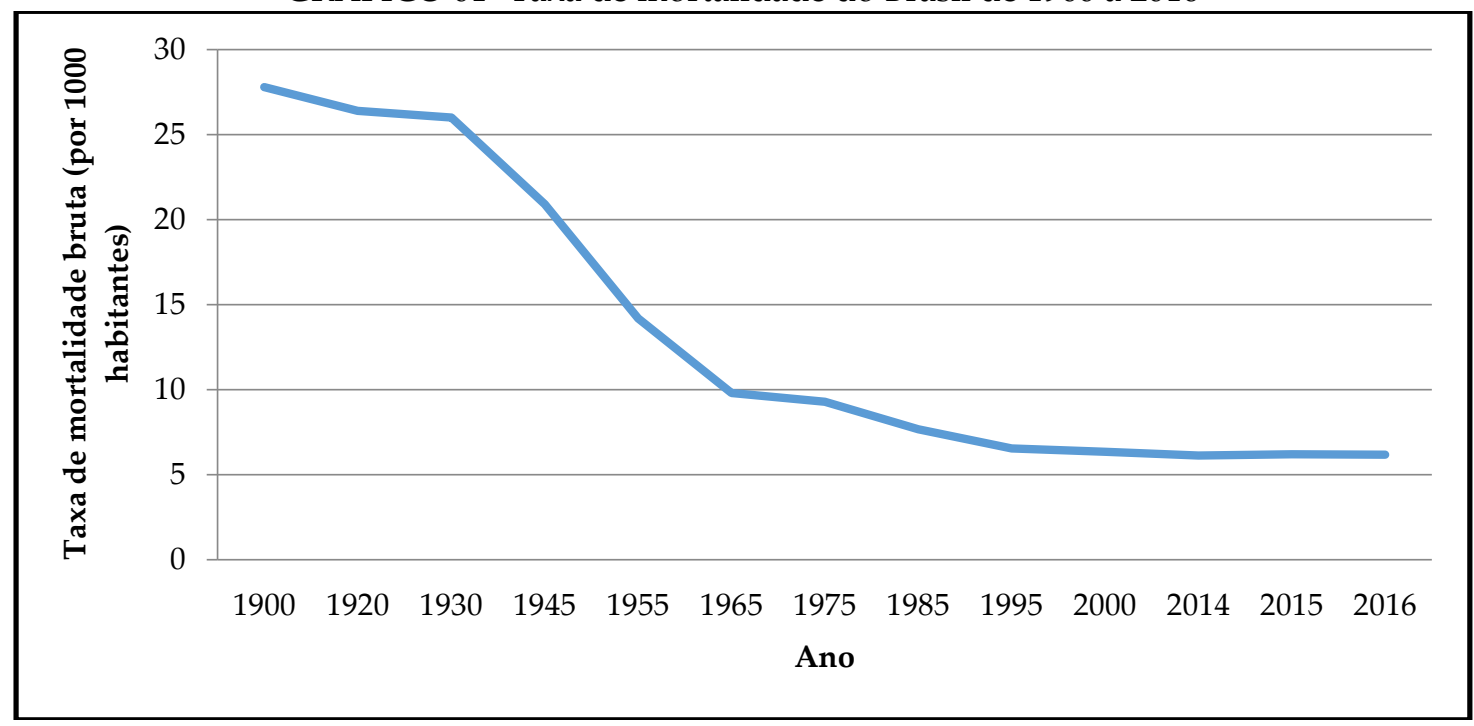

Fonte: Adaptado com base nos dados do IBGE, 2008 e Banco Mundial, 2018.

GRÁFICO 02- Taxa de fecundidade total do Brasil de 1940 a 2016 


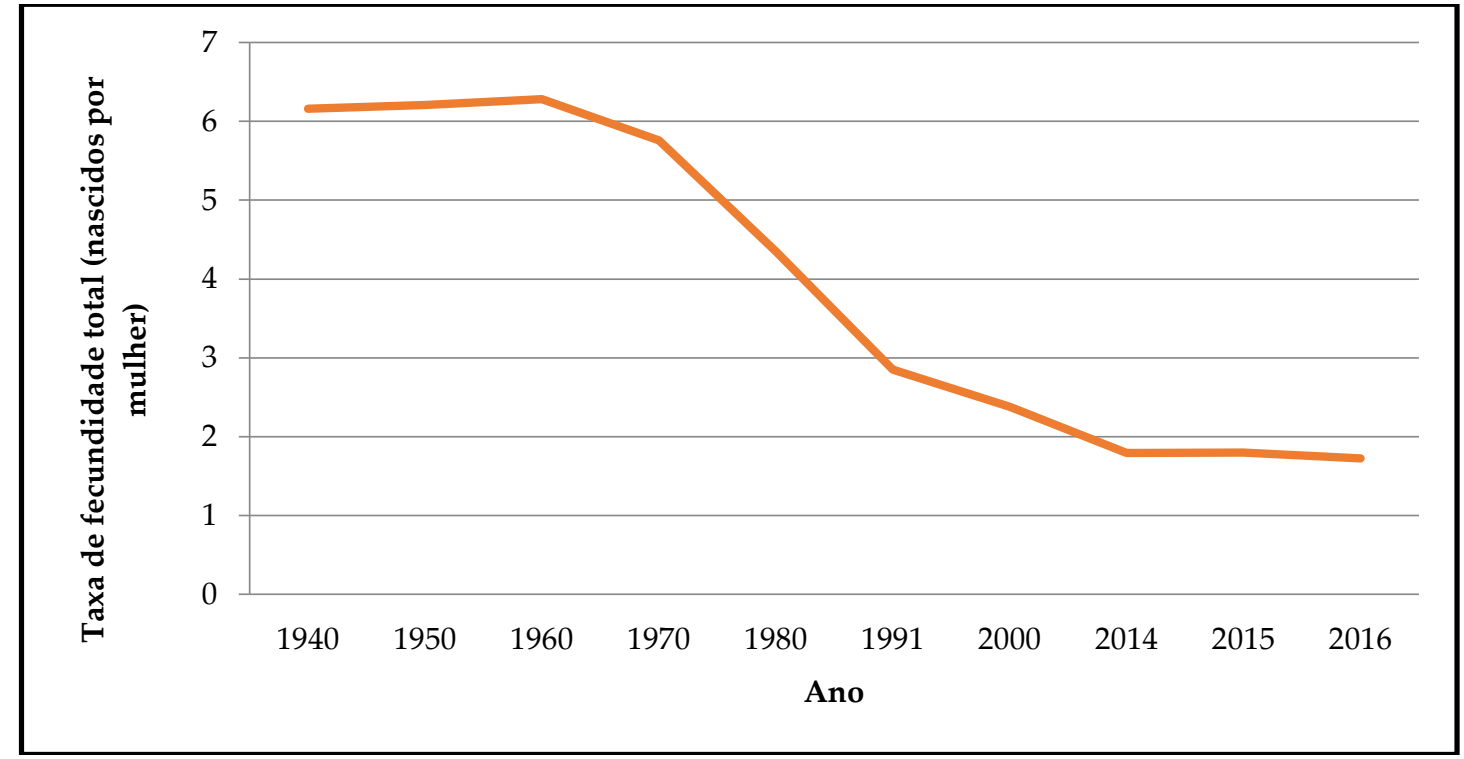

Fonte: Adaptado com base nos dados do IBGE, 2004 e Banco Mundial, 2017.

As mudanças na estrutura etária do país decorrente da transição demográfica, em determinado instante, passam por um momento em especial, o chamado bônus demográfico (ou janela de oportunidades), que se trata da situação em que a população em idade ativa (PIA- 15 a 64 anos) apresentará a maior participação em relação à população total e aos grupos etários extremos (população de 0-14 anos e de 65 anos ou mais), cujo auge acontecerá no Brasil aproximadamente em 2022 (Goiás, 2013). Neste período, cabe ao país aproveitar essa janela de oportunidades que se abre, onde haverá mais força de trabalho (Bruno, 2007) para impulsionar a economia do país.

Com o fim do bônus demográfico e o envelhecimento da PIA chegará à última fase da transição demográfica, quando as taxas de natalidade e de mortalidade crescem em um nível próximo de zero, e há a continuação do aumento significativo de idosos (65 anos ou mais) em relação à população total, fase que ocorrerá no Brasil por volta de 2050 (Brito, 2007; IBGE, 2018).

Esse cenário já é o que muitos países europeus enfrentam, por exemplo, a Itália, cuja estrutura etária (Gráfico 04) evidencia uma quantidade maior de idosos em relação ao número de jovens. Ao comparar a estrutura etária desse país, em 2016, com a do Brasil no mesmo período (Gráfico 03), observa-se uma discrepância, pois pelo Brasil ainda ser considerado um país jovem, este apresenta uma proporção de jovens maior que a de idosos, enquanto a Itália, devido a estar passando pelas últimas fases da transição demográfica, expõe uma proporção de idosos maior que a de jovens. 


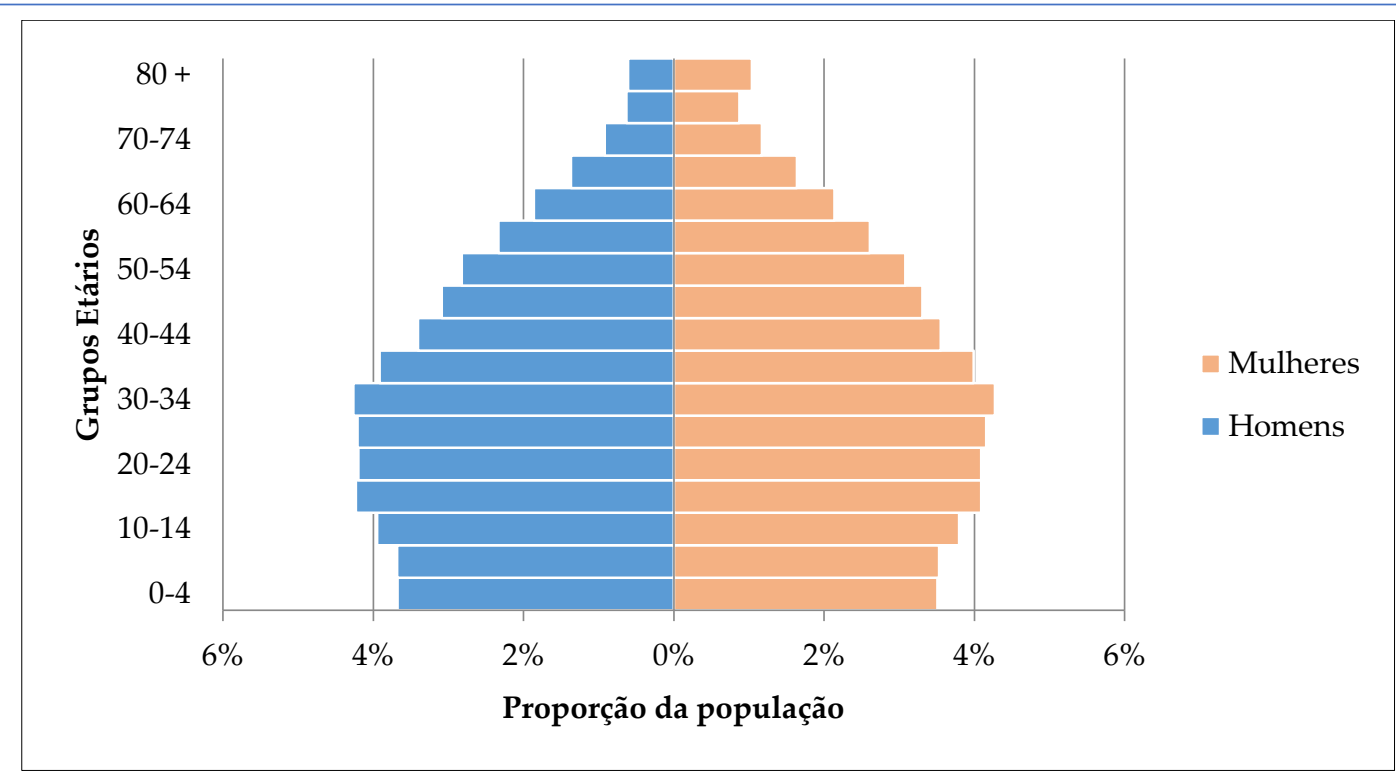

Fonte: Adaptado com base nos dados do Banco Mundial, 2018.

GRÁFICO 04- Estrutura Etária da Itália em 2016

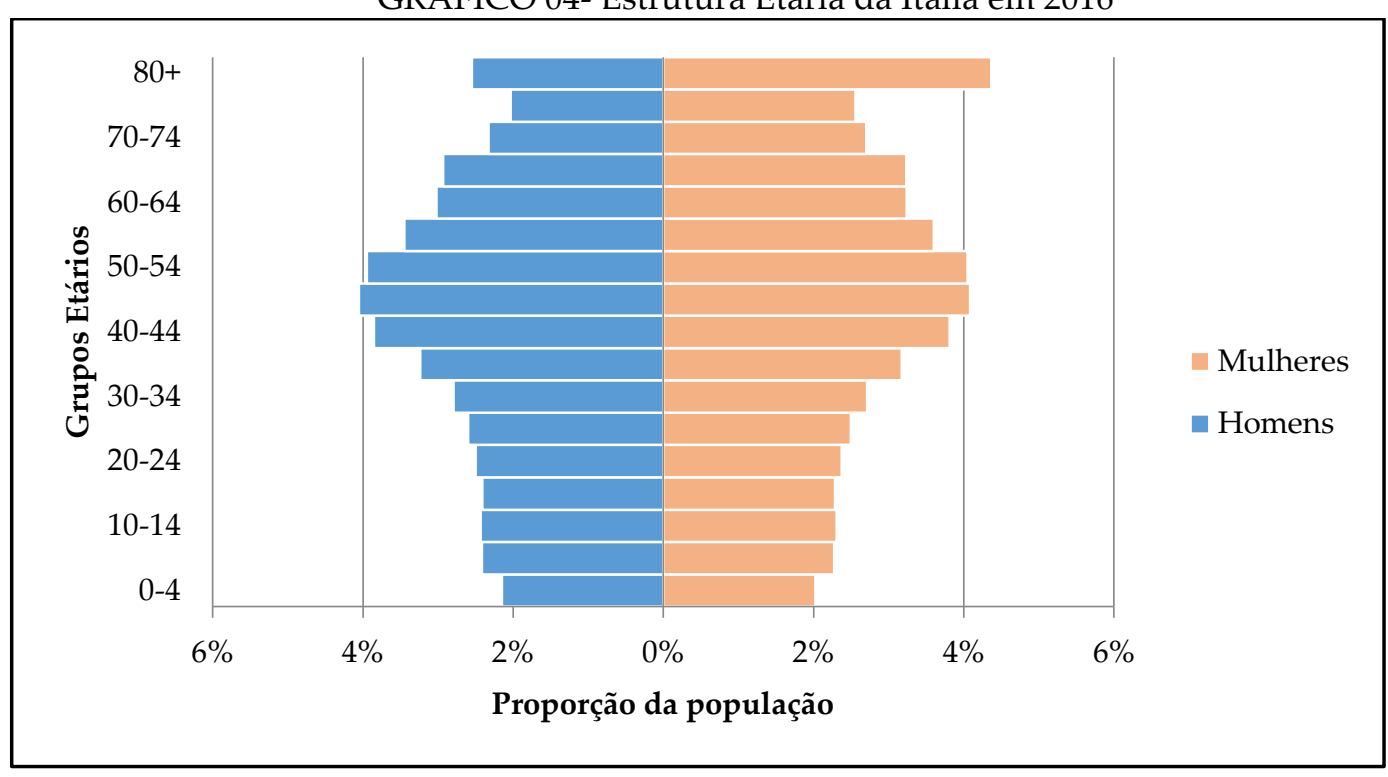

Fonte: Adaptado com base nos dados do Banco Mundial, 2018. 
A nova estrutura etária da população brasileira, esperada para 2050, acarretará desafios para as políticas públicas, principalmente em relação aos jovens e idosos. As escolas serão uma das políticas beneficiadas com essa mudança, decorrentes do pressuposto que o tamanho da população com menos de 15 anos diminuirá até 2050 (IBGE, 2018). Esta situação oferecerá oportunidades demográficas claras para se chegar a uma educação, nos níveis fundamental e médio, universal e de qualidade (Carvalho \& Wong, 2006).

As políticas públicas voltadas aos idosos, como saúde e previdência social, sofrerão um incremento considerável de demandantes, decorrentes do envelhecimento populacional brasileiro, e como consequência o governo precisará destinar mais recursos à saúde dessa massa populacional. Quanto à previdência social, segundo Brito (2007), o sistema de previdência social brasileiro, no qual, em princípio, há a contrapartida da parte dos futuros beneficiários, não está adequado à nova situação demográfica do país, isso porque para se manter a sustentabilidade do sistema previdenciário brasileiro é necessário que haja um equilíbrio entre os pagamentos de benefícios e as contribuições (regime de repartição simples), e como pode ser visto no Gráfico 05, o número de jovens para custear os benefícios reduzirá em proporções cada vez maiores, passando de $28 \%$ em 2010 para 18\% em 2050, enquanto a de idosos (beneficiários) chegará a 19\% em 2050.

GRÁFICO 05- População brasileira jovem e idosa em porcentagem de 1940 a 2050.

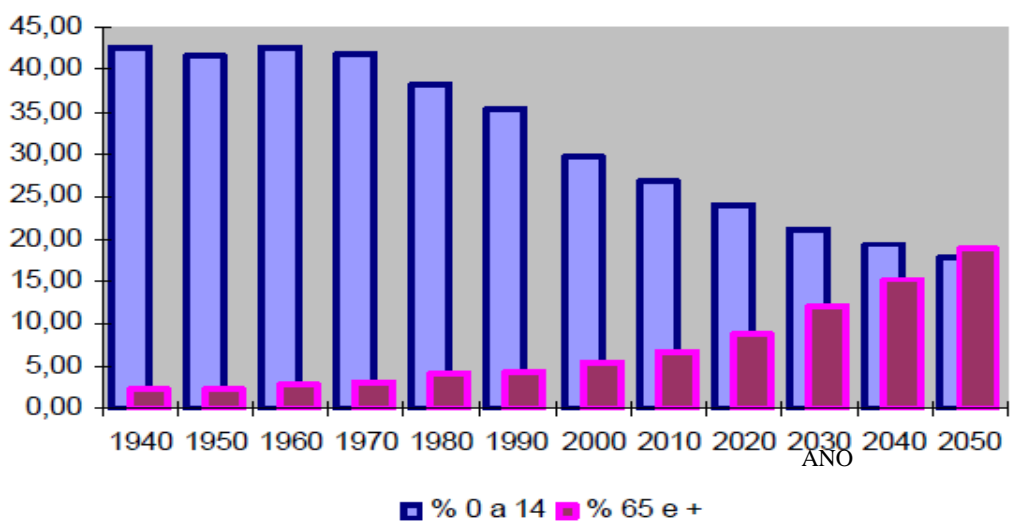

Fonte: Brito, 2007.

Um comportamento similar observa-se ao relacionar as taxas de crescimento populacional da PIA e da população idosa (PI) entre 2010 e 2050 (Gráfico 06). Enquanto a variação do crescimento da PI tende a ser positiva e relativamente alta, da PIA decresce no decorrer dos anos, chegando a ser negativo em 2050. Essa característica da estrutura populacional pode ocasionar em problemas na sustentabilidade do sistema previdenciário.

GRÁFICO 06- Variação das taxas de crescimento da população em idade ativa (PIA) e da população idosa

(PI), entre 2010 e 2050. 


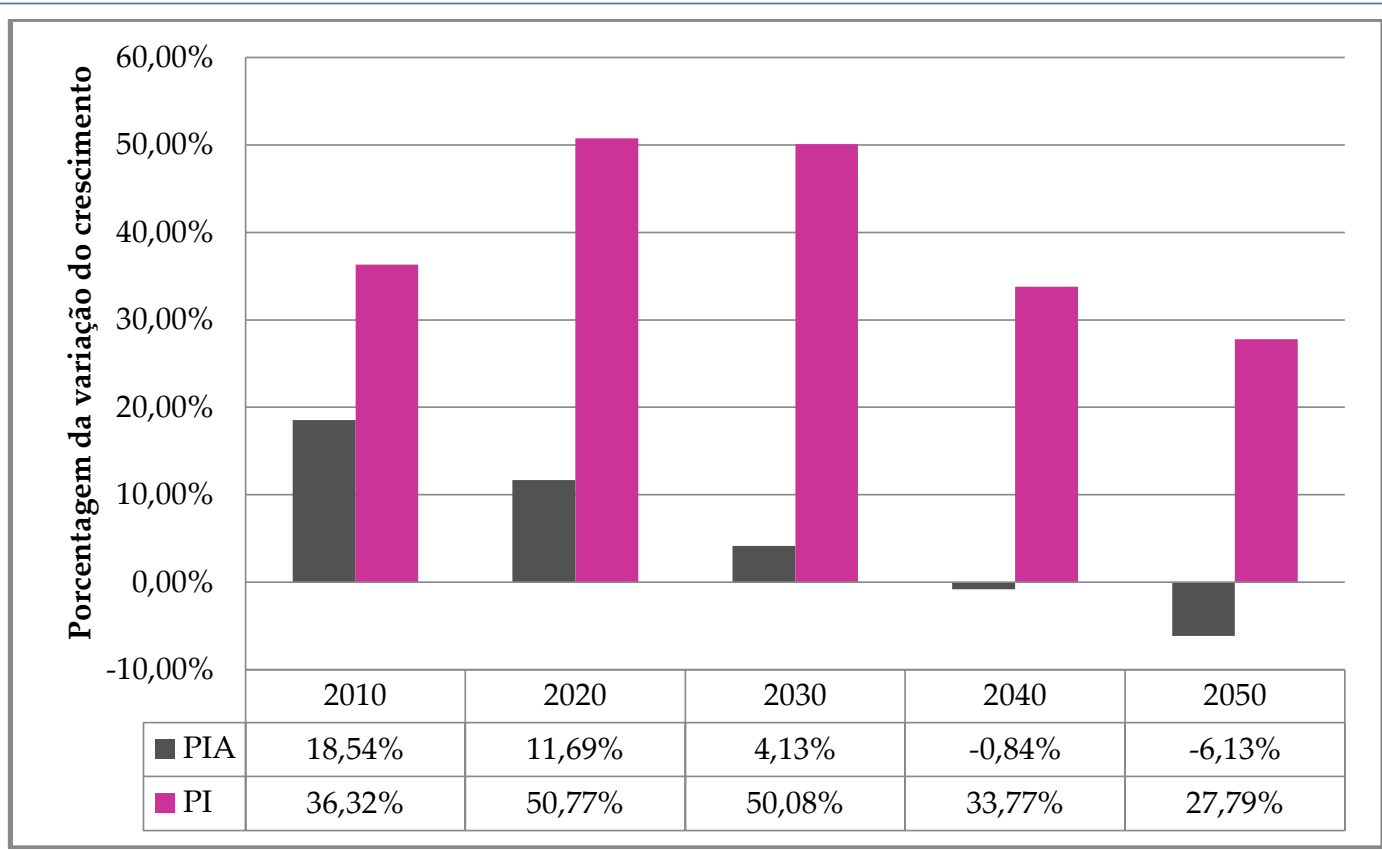

Fonte: Adaptado de Projeção da População do Brasil do IBGE, 2013.

\subsection{Previdência Social Brasileira}

Segundo o artigo 194 da Constituição Federal Brasileira/1988: “A seguridade social compreende um conjunto integrado de ações de iniciativa dos Poderes Públicos, destinadas a assegurar os direitos relativos à saúde, à previdência e à assistência social". O que diferencia essas ações sociais é a forma de acesso a elas e seu objetivo (Kertzman \& Martinez, 2014). O acesso à saúde é um direito de todos os cidadãos, não necessitando haver uma contribuição, cuja finalidade é oferecer um sistema para atender às necessidades da população em relação a problemas de saúde.

A assistência social visa o atendimento às necessidades básicas daquelas pessoas ditas em situação de risco, ou seja, que não possuem condições de suprir suas próprias necessidades básicas, e como afirma o art. 203 da Constituição Federal/88: “A assistência social será prestada a quem dela necessitar, independente de contribuição à seguridade social".

Já a previdência social, segundo Kertzman e Martinez (2014), desde que precedida de contribuição, tem por meta a cobertura dos eventos de doença, invalidez, morte, idade avançada, afastamento decorrente da maternidade, desemprego involuntário e, para os que têm baixa renda, reclusão e acréscimo das despesas familiares pela existência de filhos menores.

A previdência social brasileira está organizada em três regimes previdenciários: Regime Geral de Previdência Social- RGPS (INSS); Regime Próprio de Previdência Social- RPPS (Servidores públicos efetivos) e a Previdência complementar (pública e privada) (Kertzman \& Martinez, 2014).

O regime geral de previdência social (RGPS) abrange os trabalhadores da iniciativa privada e os servidores públicos celetistas, é de filiação obrigatória, garantindo aos segurados uma renda (até o teto de R \$ 5.839,45 - referente a 2019) em caso da ocorrência de eventos que tirem sua capacidade de trabalho. Para quem trabalha de forma autônoma, a filiação ao RGPS é facultativa, tendo que se inscrever e contribuir mensalmente ao regime.

O regime próprio de previdência social (RPPS) abrange os servidores públicos de cargo efetivo da União, dos Estados, do Distrito Federal, dos Municípios, e os militares dos Estados e do Distrito Federal (Lei no 9717/98). De filiação obrigatória, os RPPSs são organizados e administrados em cada ente federativo, com exceção dos militares federais, cujos RPPSs são administrados pelo governo federal (Silva, 2013).

A previdência complementar, que pode ser pública ou privada, é organizada de forma autônoma ao regime geral de previdência social e sua filiação é facultativa (art.202 da CF/88). A intenção 
de quem procura se filiar a esse tipo de previdência, geralmente, é de aumentar o seu benefício ao se aposentar. A previdência complementar pública pode ser contratada por todo cidadão que deseja ingressar em um desses planos, enquanto a previdência complementar privada aceita apenas pessoas que integram um determinado grupo, normalmente vinculado a uma empresa ou a um conglomerado (Beltrão, Leme, Mendonça, \& Sugahara, 2004).

\subsubsection{Regimes Financeiros}

Segundo Lima e Diniz (2016), os regimes financeiros de um sistema previdenciário referemse aos mecanismos de determinação e da captação dos montantes das contribuições financeiras para o pagamento dos benefícios prometidos. Existem três tipos de regimes financeiros: repartição simples, repartição de capitais de cobertura e capitalização.

No regime financeiro de repartição simples as contribuições arrecadadas em um exercício serão utilizadas para pagar os benefícios desse mesmo exercício, e, portanto, não há a constituição de reservas garantidoras, havendo o chamado princípio da solidariedade intergeracional (Barros, 2012) e sendo assim muito vulnerável às mudanças demográficas. O RGPS é fundado sobre o princípio da repartição simples e atualmente a sua insustentabilidade é coagitada, principalmente, pela transição demográfica, com a mudança da pirâmide populacional e com o aumento da expectativa de vida (Paz \& Pinto, 2010).

No regime financeiro de repartição de capitais de cobertura (RCC) as contribuições arrecadadas em um período serão utilizadas para a constituição de uma reserva para o pagamento dos benefícios iniciados no mesmo período, é recomendado para financiar benefícios de renda, cujas probabilidades de ocorrências se demonstrem estáveis ao longo do tempo. (Paz \& Pinto, 2010).

Já no regime financeiro de capitalização as contribuições recolhidas de cada segurado, durante sua fase laboral, são revertidas para formar uma reserva garantidora que será utilizada para os pagamentos os benefícios desse mesmo segurado (Paz \& Pinto, 2010).

Inicialmente a previdência social brasileira era instituída no sistema de capitalização, mas na década de 1950, em razão da má aplicação dos recursos arrecadados, não conseguiu se manter tal sistema, implicando a adoção do sistema de repartição simples, no entanto tal sistema é tido como inadequado frente às mudanças demográficas, econômicas e sociais ocorridas na país (Matos \& Melo, 2013).

\subsubsection{Reformas Previdenciárias}

Segundo Brasil (2002), não há muito tempo havia poucos aposentados e muitos contribuintes, cenário demográfico ideal para um regime de previdência que funciona sob o sistema de repartição simples. No entanto, esse sistema no Brasil ultrapassou seus limites em relação à razão de dependência entre contribuintes e beneficiários, que em 1950 havia 7,89 contribuintes financiando cada beneficiário, e em 1970 esta relação chegou a 1,70. Esse fenômeno ocorreu principalmente em função das regras de acesso a benefícios previdenciários, e devido às mudanças demográficas, que passariam, após as reformas, a ser determinantes sobre o futuro do sistema.

Frente a este cenário em que o Brasil se encontrava, em 1998, houve a primeira grande reforma, quando foi aprovada a emenda constitucional no 20/1998, que trazia mudanças consideráveis para a previdência social brasileira, como a eliminação da aposentadoria proporcional e a instituição, para os servidores públicos, da idade mínima de aposentadoria integral (60 anos para homens e 55 anos para mulheres). No entanto, em 1999, houve a aprovação da lei nº 9.816/1999, também relacionada à reforma da previdência, que criou o fator previdenciário e a desconstitucionalização da fórmula do cálculo de aposentadoria, que passava a ser calculado baseado nos $80 \%$ maiores salários do contribuinte desde julho de 1994 até o momento da aposentadoria (Rocha \& Caetano, 2008). 
A segunda grande reforma que a previdência passou foi através das emendas constitucionais no 41/2003 e a no 47/2005, no governo Lula. Decorrente da presença do déficit da previdência social que continuou sua trajetória ascendente, especialmente a parcela advinda do regime previdenciário dos servidores públicos (Amaro, 2011). Sucedidas destas, as mudanças ocorreram principalmente em relação ao RPPS, com a criação da contribuição previdenciária para inativos e a imposição do teto na concessão dos benefícios dos servidores públicos.

No entanto, mesmo com a ocorrência dessas reformas, em 2015, devido novamente a ascensão do déficit previdenciário, fez-se necessária outra mudança, desta vez no governo Dilma, através das leis de $\mathrm{n}^{\mathrm{o}}$ 13.134/15, 13.135/15 e 13.183/15.

A lei 13.134/15 alterou as regras para a concessão do seguro desemprego e do abono anual. As mudanças decorrentes da lei 13.135/15 foram principalmente na pensão por morte, no auxílio doença e no tempo exigido de união estável ou de casamento, para o pagamento da pensão ao cônjuge (beneficiário). Já decorrente da lei 13.183/15 houve a implementação da regra 85/95 para a concessão da aposentadoria integral.

\subsubsection{Déficit Previdenciário}

Periodicamente a imprensa vem divulgando que a previdência social brasileira está prestes a entrar em um grande colapso financeiro devido à imensa diferença, na casa de dezenas de bilhões de reais anuais, entre os gastos com direitos e serviços previdenciários e a arrecadação destinada a financiar a previdência social pública. Essa diferença negativa entre receitas e despesas é denominada déficit. (Souza, 2011). Tal notícia vem gerando preocupação quanto à sustentabilidade do sistema previdenciário.

O déficit vem evoluindo de forma crescente durante os anos, e essa situação se reflete tanto para o RGPS quanto ao RPPS. No Gráfico 07 têm-se o resultado negativo do RGPS, onde pode-se observar que o seu progresso está cada vez mais considerável, de 2015 para 2016 houve o aumento de cerca de $75 \%$, enquanto em 2017 ocorreu um acréscimo de $22 \%$.

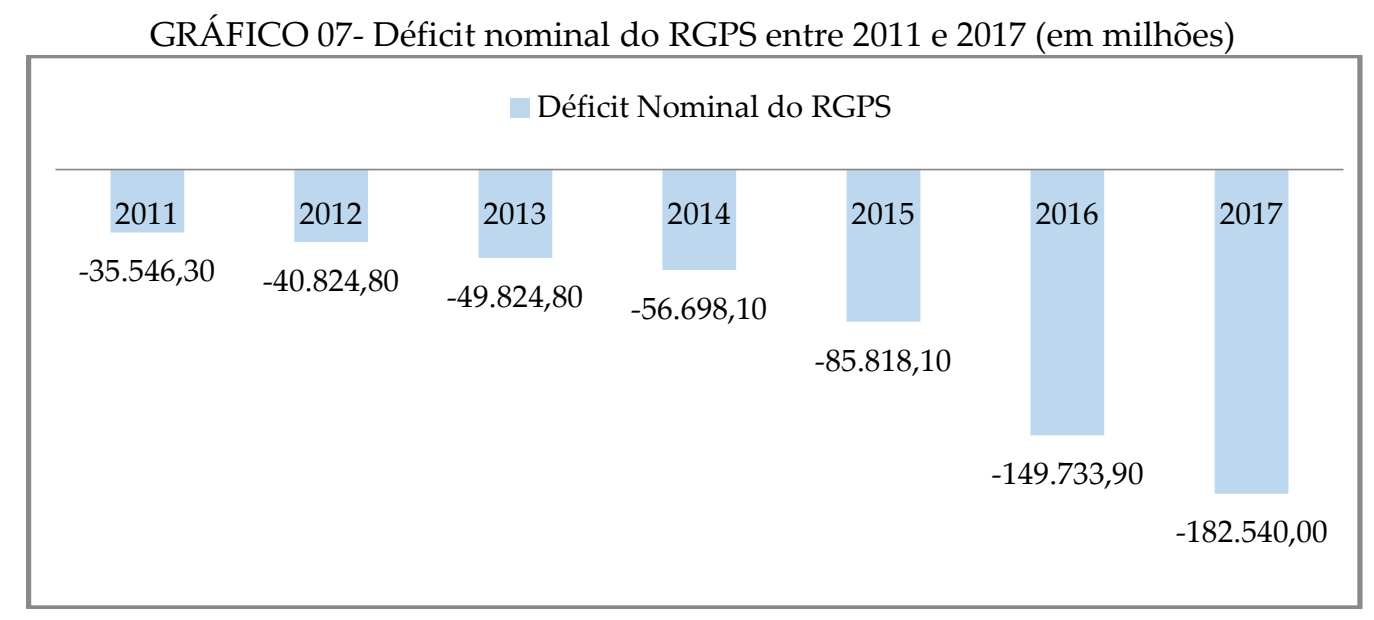

Fonte: Adaptado de Secretaria de Previdência, 2019.

Já no Gráfico 08 há os resultados referentes aos RPPSs do Brasil, destrinchados por tipos. Apesar da administração da maioria dos RPPSs pertencer a cada ente federativo, nota-se a mesma crescente quanto à insuficiência de recursos para suprir as responsabilidades financeiras.

GRÁFICO 08- Evolução do resultado atuarial por tipo de RPPS entre 2011 e 2018 (em bilhões) 


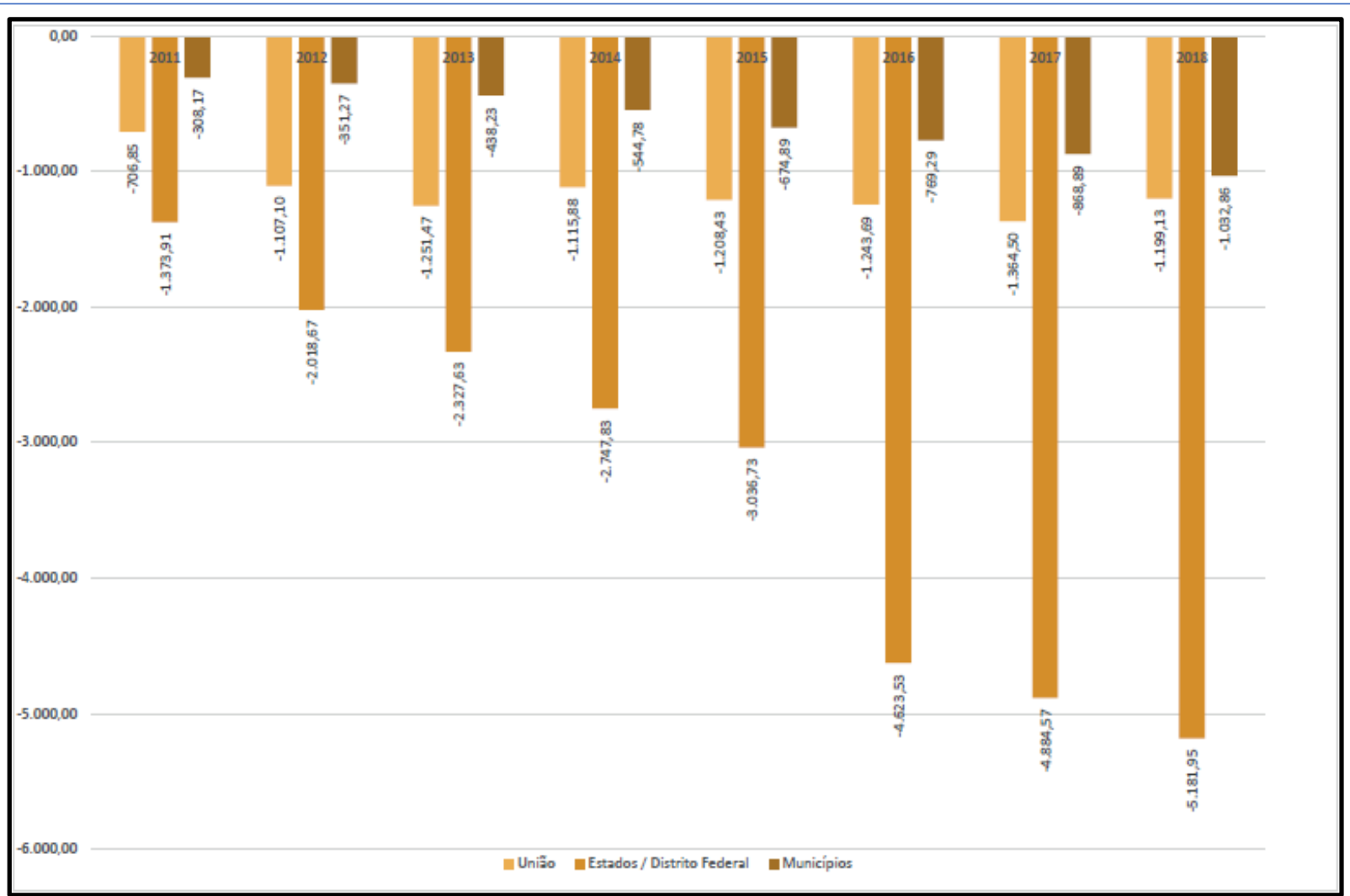

Fonte: Anuário Estatístico da Previdência Social (AEPS), 2017.

No entanto, há autores que afirmam a existência de superávit previdenciário. Segundo Souza (2011), o discurso oficial do déficit previdenciário baseia-se em uma interpretação errada da titularidade e da distribuição dos recursos provenientes da arrecadação das contribuições. A aceitação passiva destes dados falaciosos decorre do desconhecimento da população em geral e da imobilidade dos órgãos representativos das classes envolvidas.

Através da criação da Desvinculação das Receitas da União (DRU), em 1994, o governo ficou autorizado a utilizar até $20 \%$ dos recursos advindos de tributos, contribuições previdenciárias e de outras verbas para pagamento de qualquer despesa considerada prioritária. Entretanto, mais do que o limite permitido, está sendo utilizado, e isso provoca um rombo no montante repassado à seguridade social (Gentil, 2006).

Assim, as discussões sobre a existência ou não do déficit vem se perdurando, com ambas as partes mostrando provas e defendendo seus pontos de vista. Entretanto, o discurso oficial proveniente do Governo é de que há a existência do déficit. Deste modo, dada as mudanças demográficas observadas, aliadas à falta de recursos previdenciários, o Governo apresenta-se passível para a realização de uma nova reforma previdenciária, através da Proposta de Emenda à Constituição 06/2019 (PEC-06/2019), aprovada pela Câmara dos Deputados, cujas propostas estão sendo analisadas pelos senadores. Entretanto, tal reforma enfrenta muitas resistências na sociedade, devido aos seus termos (Lobato, Costa, \& Rizzotto, 2019).

\subsection{Implicações do Envelhecimento Populacional na Previdência Social}

Países da Europa como a Itália, Alemanha e Grécia já enfrentam os efeitos do final da transição demográfica (Salvati, Carlucci, Serra, \& Zambon, 2019), quando suas taxas de fecundidade e mortalidade se encontram em níveis baixos e o crescimento da população é próximo de zero. Como pode ser visto nos Gráficos 09 e 10, a fecundidade desses países se encontram abaixo de nível de reposição (2,1 por mulher), em torno de 1,5 na Alemanha, 1,3 na Grécia e 1,4 na Itália, em 2016, e a taxa de mortalidade também se encontra em níveis baixos. 
Essas mudanças demográficas, aliadas com o aumento da expectativa de vida, provocaram desafios em relações às políticas públicas desses países. Um dos problemas de destaque é a redução da população economicamente ativa (15-64 anos) na Europa, que é a parte da população responsável pela circulação da economia e principalmente por custear os benefícios previdenciários pagos aos inativos, devido ao sistema de repartição simples da previdência dos países europeus.

Da Espanha à França, passando da Alemanha à Grécia, governos buscam fórmulas para recriar um sistema de aposentadorias e de contribuição social que seja sustentável para lidar com um número cada vez maior de idosos na economia. Medidas como o aumento da idade de aposentadoria e do tempo de contribuição estão sendo tomadas, como forma de minimizar o déficit presente nas contas públicas. Pela primeira vez na história do continente, um terço da população estará aposentada, assim, as estimativas são de que, em 30 anos, dois terços dos europeus sustentarão um terço. O custo com saúde pública está cada vez mais crescente, no Reino unido, por exemplo, os gastos com saúde já são superiores aos gastos com educação para as crianças (Chade, 2010).

GRÁFICO 09- Taxa de fecundidade total da Alemanha, Grécia e Itália de 1970 a 2016.

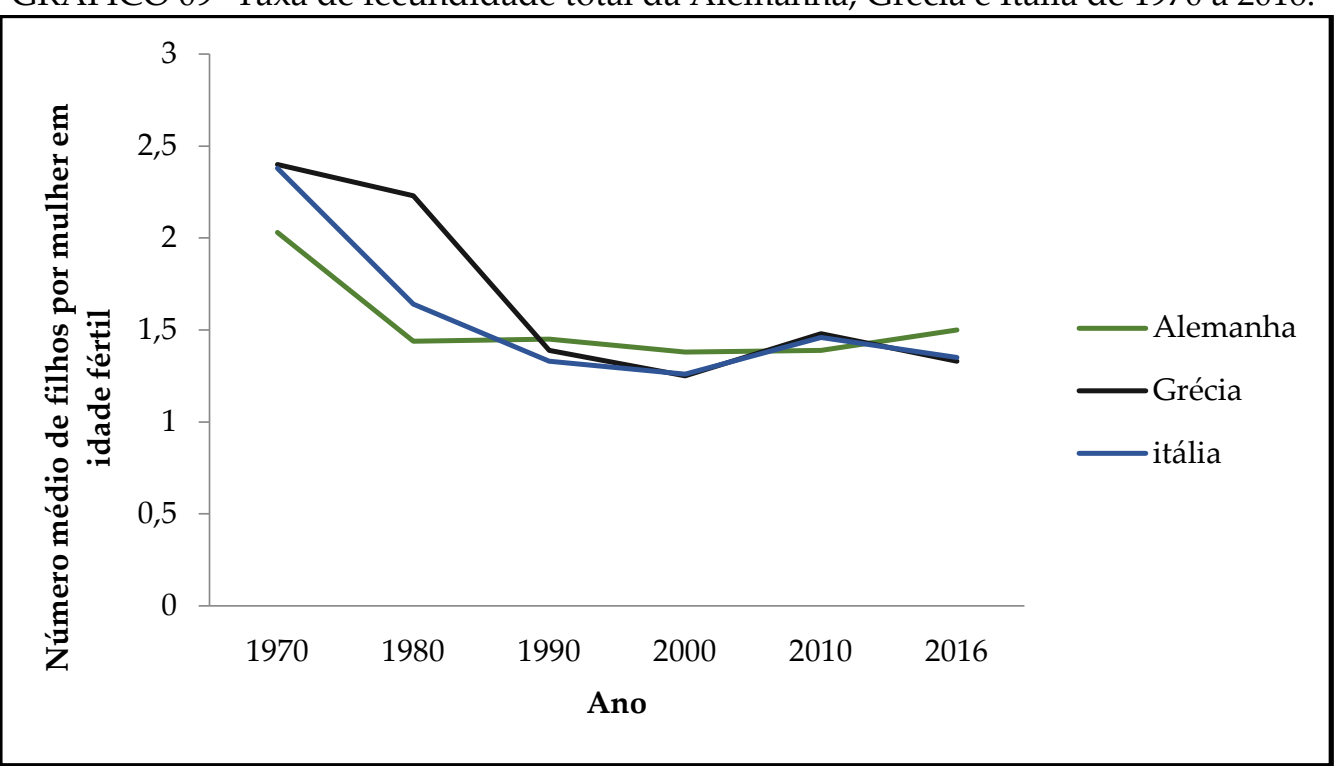

Fonte: Adaptado do Banco Mundial, 2016.

GRÁFICO 10- Taxa de mortalidade bruta da Alemanha, Grécia e Itália de 1970 a 2016. 


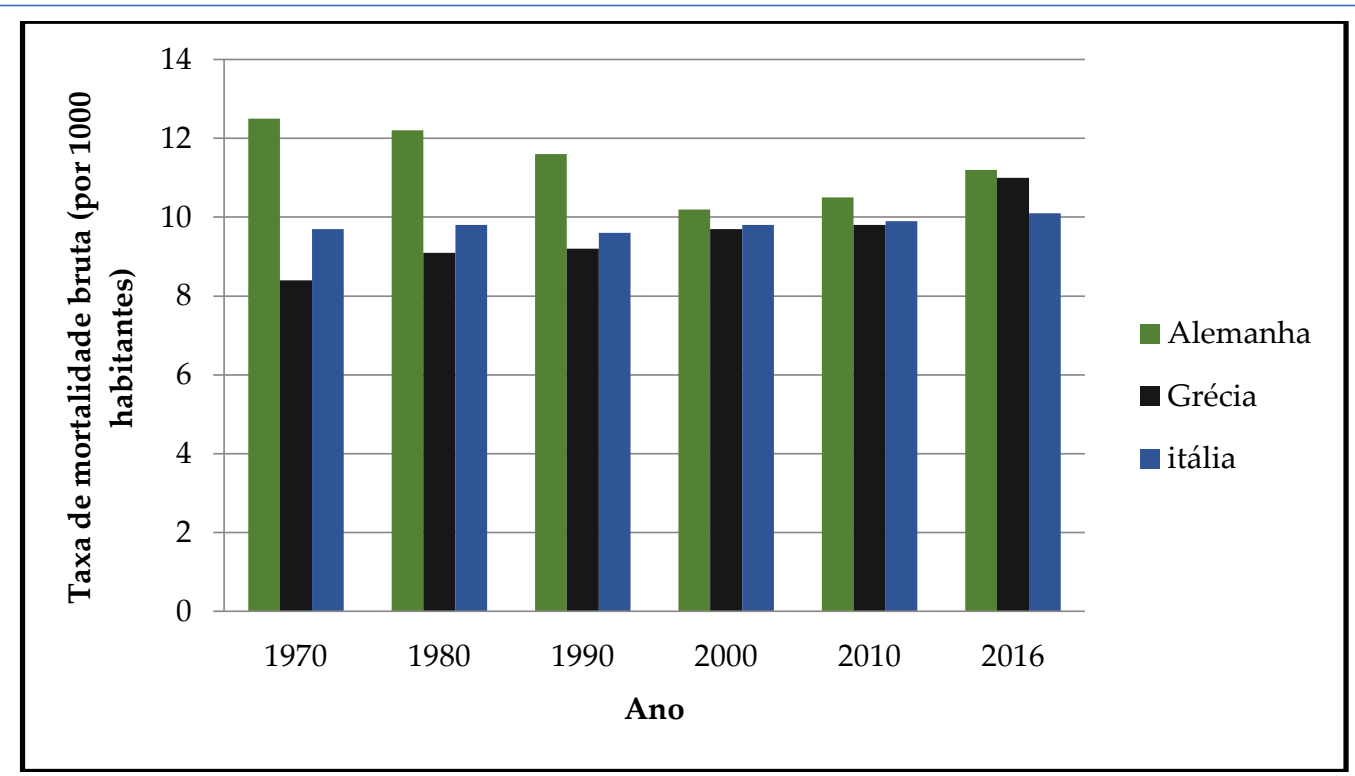

Fonte: Adaptado do Banco Mundial, 2016.

É importante ressaltar que o processo de envelhecimento populacional está ocorrendo no Brasil de forma mais acelerada do que ocorreu na Europa (Brito, 2007), e por isso espera-se que os efeitos dessa mudança na estrutura etária da população provoquem efeitos muito mais rápidos do que aconteceu nos países europeus.

Os gastos previdenciários desses países em relação ao PIB, comparados com o do Brasil, mostram uma diferença exorbitante, como pode ser visto no Gráfico 11, em que correlaciona a razão dependência dos idosos RDI (divisão entre a população de 65 anos ou mais com a população em idade ativa, 15 a 64 anos) com os gastos previdenciários em relação ao PIB.

Apesar do Brasil ter uma RDI baixa, em torno de menos 10\%, sendo considerado um país que ainda possui uma população jovem, seus gastos previdenciários são equivalentes aqueles com a RDI alta, ou seja, aos países com altos índices de idosos. Segundo Rocha e Caetano (2008), países com a estrutura demográfica similar à brasileira gastam com a Previdência cerca de $4 \%$ do seu PIB, enquanto países com despesa previdenciária da magnitude da brasileira têm uma RDI em trono de 27\%. Em resumo, países com a estrutura etária brasileira despendem 1/3 do que o Brasil gasta, enquanto nações que destinam quantias semelhantes às despendidas pela Previdência brasileira são três vezes mais velhas.

GRÁFICO 11- Despesas previdenciárias e razão dependência dos idosos, do Brasil em relação a outros países (incluindo os da Europa).

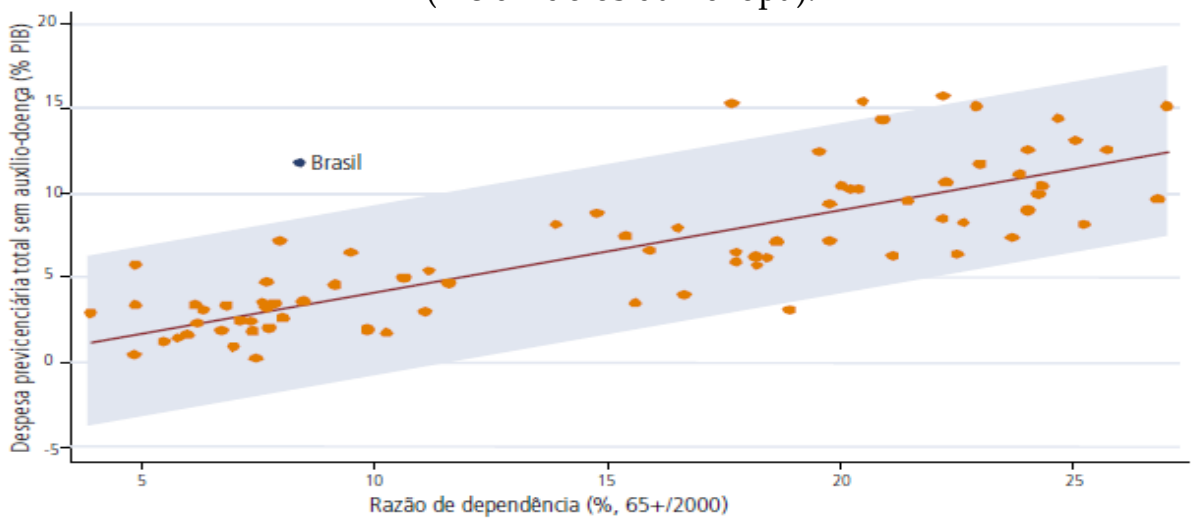

Fonte: Rocha e Caetano (2008).

Portanto, se com a estrutura etária ainda não envelhecida, o Brasil já possui grandes gastos previdenciários, quando chegar à última fase da transição demográfica, em que a população de ido- 
sos será superior ao de jovens, espera-se que os gastos irão aumentar ainda mais e o déficit será cada vez mais ascendente, chegando ao ponto de se questionar a sustentabilidade do sistema previdenciário brasileiro (Costanzi, 2016).

Alguns autores já abordam este tema, como Bruno (2007) no artigo "Transição demográfica e regime de acumulação financeirizado no Brasil: "Bônus" ou "Ônus" para a previdência social?". Neste trabalho o autor cita mais o lado econômico da transição demográfica, enfatizando o bônus demográfico, afirmando que o sistema de seguridade social precisa aproveitar o lado benéfico deste processo para poder suprir as suas obrigações futuras. Outra autora que tratou do tema foi Lima (2013) na tese "A dinâmica demográfica e a sustentabilidade do modelo de financiamento do regime geral de previdência social", onde projeta a situação financeira do RGPS através da técnica de simulação Monte Carlo, no período de 2003 a 2030, obtendo que a dinâmica demográfica deste mesmo período afetou as receitas e despesas previdenciárias, devido ao aumento da população idosa em relação à jovem, influenciando no equilíbrio nas contas previdenciárias.

Por sua vez, Costanzi e Ansiliero (2017), utilizando um modelo simplificado com variáveis econômicas e demográficas, tentaram quantificar o impacto da transição demográfica na despesa da Previdência Social em relação ao PIB até 2060 e 2100. Os resultados encontrados pelos autores indicam um notável incremento das despesas em razão do processo de envelhecimento populacional.

Todos esses trabalhos citados se alinham em certa medida com o objetivo proposto neste artigo. No entanto, este ensaio se diferencia por utilizar uma metodologia puramente demográfica, cuja complexidade é relativamente simples, além de avaliar isoladamente o efeito da transição demográfica nas despesas previdenciárias do Regime Geral.

\section{METODOLOGIA}

Para alcançar os objetivos deste trabalho, foram realizadas pesquisas bibliográficas por meio de jornais, revistas, livros, artigos e meios eletrônicos com a finalidade de analisar o processo da transição demográfica brasileira, evidenciando a sua evolução e consequências.

Foram utilizados dados sobre as populações brasileira e italiana referentes a 2016, coletados no Banco Mundial, além de informações sobre os gastos previdenciários com benefícios concedidos em relação a 2016. O uso da população da Itália como referência para os cálculos decorreu devido a esta já estar vivenciando a última fase da transição demográfica (Gráfico 04) e por mostrar-se mais compatível com a estrutura etária que o Brasil vivenciará neste mesmo período.

Os dados sobre os gastos previdenciários do RGPS foram coletados no site do Anuário Estatístico da Previdência Social [Aeps Infologo] (base de dados históricos da previdência social). Neste sentido, foram utilizados os referentes a benefícios concedidos do ano 2016 (foram usados deste ano, pois eram os dados mais atuais na data da elaboração desta pesquisa).

De posse dessas informações, foi aplicada uma técnica demográfica conhecida como padronização direta, objetivando observar como os gastos previdenciários se comportarão em uma população mais envelhecida.

\subsection{Padronização}

A padronização é uma técnica utilizada principalmente na demografia, quando se quer comparar níveis de variáveis que sofrem influência da estrutura etária. Segundo Carvalho, Sawyer e Rodrigues (1998) não se pode comparar diferenciais de níveis a partir de taxas brutas ou gerais. Então uma das alternativas para a comparação de indicadores-síntese de diversos países ou regiões seria eliminar o efeito da composição etária sobre os indicadores que deseja-se comparar, ajustandoos segundo uma mesma distribuição etária padrão. Essa técnica, conhecida como padronização, que pode ser do tipo direta ou indireta, permite controlar ou isolar o efeito de determinadas característi- 
cas que estejam afetando a comparação, através de medidas-síntese, dos níveis de uma variável entre populações diferentes.

Para analisar o comportamento dos gastos previdenciários foi aplicada a técnica da padronização direta, onde primeiramente calcula-se uma série de taxas específicas, que representa a intensidade dos gastos em benefícios por idade, e uma taxa bruta de consumo com gastos previdenciários, que evidencia o nível de gastos totais com benefícios previdenciários para a população brasileira de 2016.

Através da padronização direta, considerando que as intensidades na concessão dos benefícios permanecerão no mesmo nível de 2016, essas taxas específicas de consumo foram aplicadas em uma nova estrutura etária (população da Itália, em 2016) para então encontrar uma nova taxa bruta padronizada.

Para Carvalho, Sawyer e Rodrigues (1998,) no cálculo de taxas brutas padronizadas por idade, pelo método direto, é necessário que se disponha do total de eventos, distribuídos por grupos de idade, e da distribuição etária das populações em estudo. Com essas informações, pode-se estimar taxas específicas por idade que, aplicadas a uma distribuirão etária padrão, fornecerão taxas brutas padronizadas, que podem ser comparadas para análise de diferencial de níveis entre várias populações. Essa comparação é possível porque, neste caso, todas as taxas referem-se a uma única distribuição etária. As diferenças entre elas serão explicadas, em princípio, pelas diferenças entre as diversas funções da variável em estudo (conjunto de taxas específicas).

Para aplicação da padronização direta foram utilizados dados sobre os gastos previdenciários divididos por grupos etários (adotados como padrão para o estudo), em relação a 2016, junto com a população do Brasil e da Itália.

De posse destes dados, o cálculo das taxas específicas de consumo foi dada da seguinte forma:

$$
{ }_{n} T E G P_{x}=\frac{{ }_{n} T G P_{x}}{{ }_{n} P_{x}}
$$

Onde ${ }_{n} T E G P_{x}$ são as taxas específicas de gastos previdenciários entre as idades $\mathrm{x}$ e $\mathrm{x}+\mathrm{n}$, ${ }_{n} T G P_{x}$ é o total de gastos previdenciários entre as idades x e x+n e ${ }_{n} P_{x}$ é a população entre as idades $\mathrm{x}$ e $\mathrm{x}+\mathrm{n}$. Obtendo-se, portanto, uma série de taxas específicas de consumo, que mostraram a intensidades dos gastos previdenciários por grupos etários e que foi utilizada para o cálculo da taxa bruta padronizada.

Também foi calculada uma taxa bruta de gastos previdenciários que dar-se de seguinte maneira :

$$
T B G P=\frac{T G P}{P}
$$

Onde TBGP é a taxa bruta de consumo com gastos previdenciários em 2016, TGP são os gastos previdenciários com benefícios em 2016 e $P$ é a população brasileira total em 2016. Essa taxa bruta representará o gasto previdenciário per capita (por habitante).

Para analisar o comportamento do consumo dos gastos previdenciários brasileiros em uma população envelhecida, como a da Itália, foi calculada a taxa bruta padronizada, cujo cálculo deu-se da forma:

$$
T B C_{p . d .}=\sum_{n} T E C_{x} *{ }_{\%} P_{x}
$$

Sendo: ${ }_{\%} P_{x}=\frac{\sum_{n} P_{x}}{\sum P_{2016}}$

Onde, $T B C_{p . d .}$ é a taxa bruta de consumo padronizada de gastos previdenciários por grupos etários, ${ }_{n} T E C_{x}$ são as taxas específicas de consumo previdenciários entre as idades $\mathrm{x}$ e $\mathrm{x}+\mathrm{n}$ observa- 
das no Brasil em 2016 , $P_{x}$ é o percentual da população italiana em 2016, que é obtido pela divisão entre a população por grupos etários em $2016\left({ }_{n} P_{x}\right)$ e a população total no mesmo ano $\left(P_{2016}\right)$.

\section{RESULTADOS}

Primeiramente foi calculada uma série de taxas específicas por idade e sexo de gastos previdenciários (TEGP) para a população brasileira de 2016, onde foi observado um comportamento diferente entre os sexos em determinados grupos etários (Gráfico 12). A intensidade dos gastos previdenciários nas idades mais jovens e mais idosas, para as mulheres, apresenta-se mais acentuada em relação à masculina, estes por sua vez apresentam uma maior intensidade nas idades adultas.

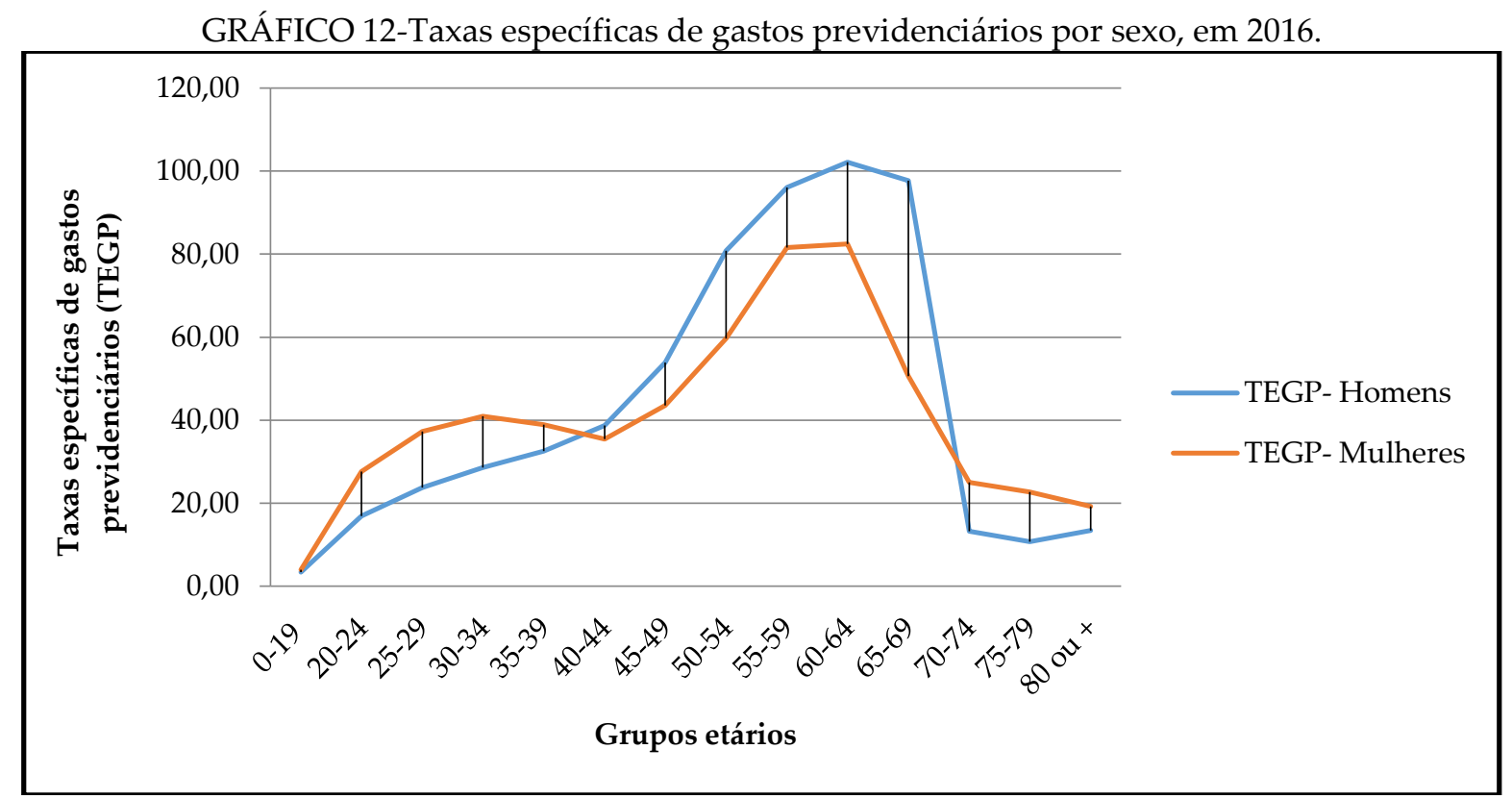

Fonte: Adaptado de Aeps InfoLogo, 2016.

Essa diferença referente à mulher nas faixas etárias mais jovens (0-39 anos) pode ser explicada pela concessão de benefícios específicos do sexo feminino, como pode ser analisado no Gráfico 13, no qual evidencia que a maioria dos benefícios concedidos às mulheres de 0 a 39 anos são referentes ao salário maternidade.

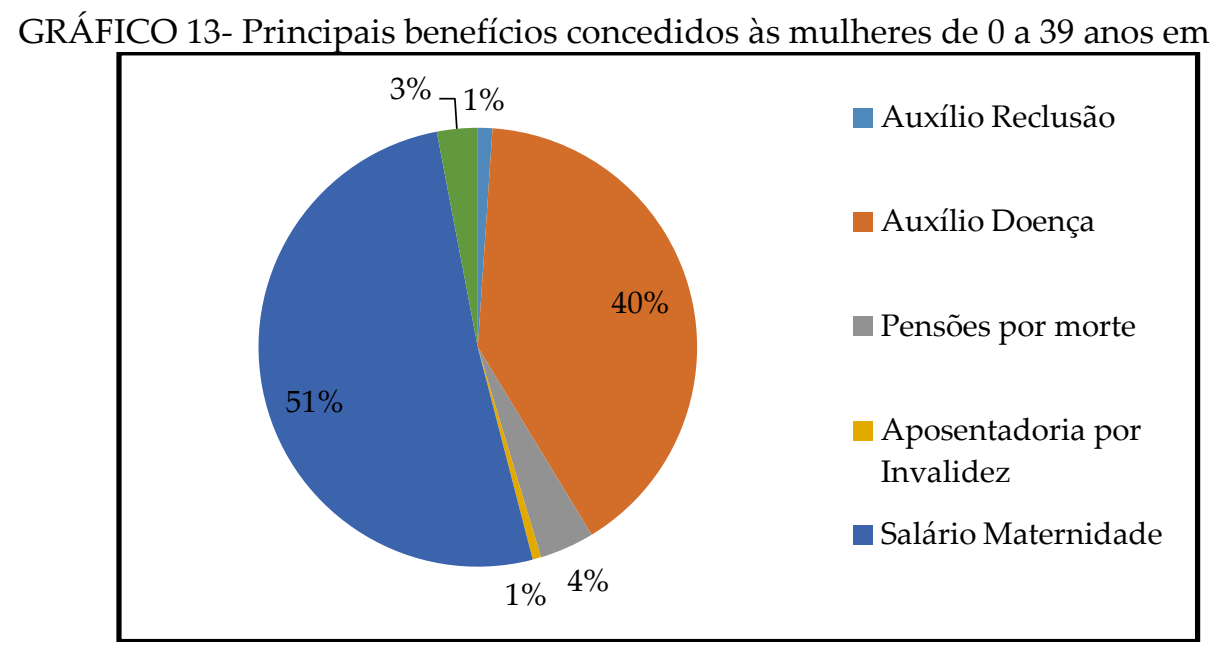

Fonte: Adaptado de Aeps InfoLogo, 2016.

Em relação aos homens do grupo etário 40 a 69 anos, a distinção na intensidade dos gastos ocorre devido à maior concentração da concessão dos auxílios acidente e doença, e das aposentado- 
rias por invalidez, e após tempo de contribuição, como pode-se verificar na Tabela 01, onde ao se comparar os valores destes benefícios concedidos, por sexo deste mesmo grupo etário, observa-se uma diferença a favor dos homens.

Tabela 01- Principais benefícios concedidos a beneficiários (por sexo) entre 40 a 69 anos em 2016.

\begin{tabular}{ccc}
\hline Tipos de Benefícios & Homens & Mulheres \\
\hline Auxílio reclusão & $\mathrm{R} \$ 45.992,32$ & $\mathrm{R} \$ 1.265 .209,44$ \\
Auxílio acidente & $\mathrm{R} \$ 2.948 .864,29$ & $\mathrm{R} \$ 641.506,80$ \\
Auxílio doença & $\mathrm{R} \$ 873.061 .061,97$ & $\mathrm{R} \$ 694.757 .840,00$ \\
Pensões por morte & $\mathrm{R} \$ 46.291 .010,91$ & $\mathrm{R} \$ 252.619 .453,14$ \\
Aposentadoria por idade & $\mathrm{R} \$ 293.392 .193,89$ & $\mathrm{R} \$ 388.714 .231,57$ \\
Aposentadoria por invalidez & $\mathrm{R} \$ 134.874 .943,83$ & $\mathrm{R} \$ 65.564 .368,59$ \\
$\begin{array}{c}\text { Aposentadoria após tempo de con- } \\
\text { tribuição }\end{array}$ & $\mathrm{R} \$ 593.629 .496,33$ & $\mathrm{R} \$ 327.562 .415,24$ \\
\hline
\end{tabular}

Fonte: Adaptado de Aeps InfoLogo, 2016.

Já nas faixas etárias mais idosas (70 - 80 anos ou mais) a divergência pode ser explicada pela expectativa de vida ao nascer feminina ser maior que a masculina, como afirma Marri, Wajnman e Andrade (2011), a diferença entre os sexos na expectativa de vida ao nascer, a favor das mulheres as torna as principais recebedoras das pensões por morte (dos maridos), este fato é considerado um dos principais fatores que causam o desequilíbrio atuarial entre os sexos na previdência social.

Além da expectativa de vida maior em favor das mulheres, outro fator que deve-se levar em consideração ao analisar essa diferença entre os sexos, é a possibilidade de acúmulo de benefícios previdenciários, que segundo os dados do Aeps Infologo, do total de beneficiários ativos em 2016, cerca de 6,31\% acumulavam algum outro tipo de benefício, e desses, aproximadamente 3,53\% eram mulheres, contra 2,78\% referente aos homens. Ou seja, além das mulheres receberem por mais tempo os benefícios, devido à em média viverem mais que os homens, algumas ainda acumulam benefícios, o que gera um custo maior para a previdência social.

Outro ponto examinado foi a distribuição da quantidade dos benefícios concedidos por sexo, onde permitiu-se constatar que tanto em termos reais (Gráfico 12) quanto em termos de quantidade (Gráfico 14), o consumo dos benefícios previdenciários é mais intenso nos grupos etários adultos, e este comportamento ocorre para ambos os sexos.

Gráfico 14- Quantidade de benefícios concedidos por sexo, em 2016. 


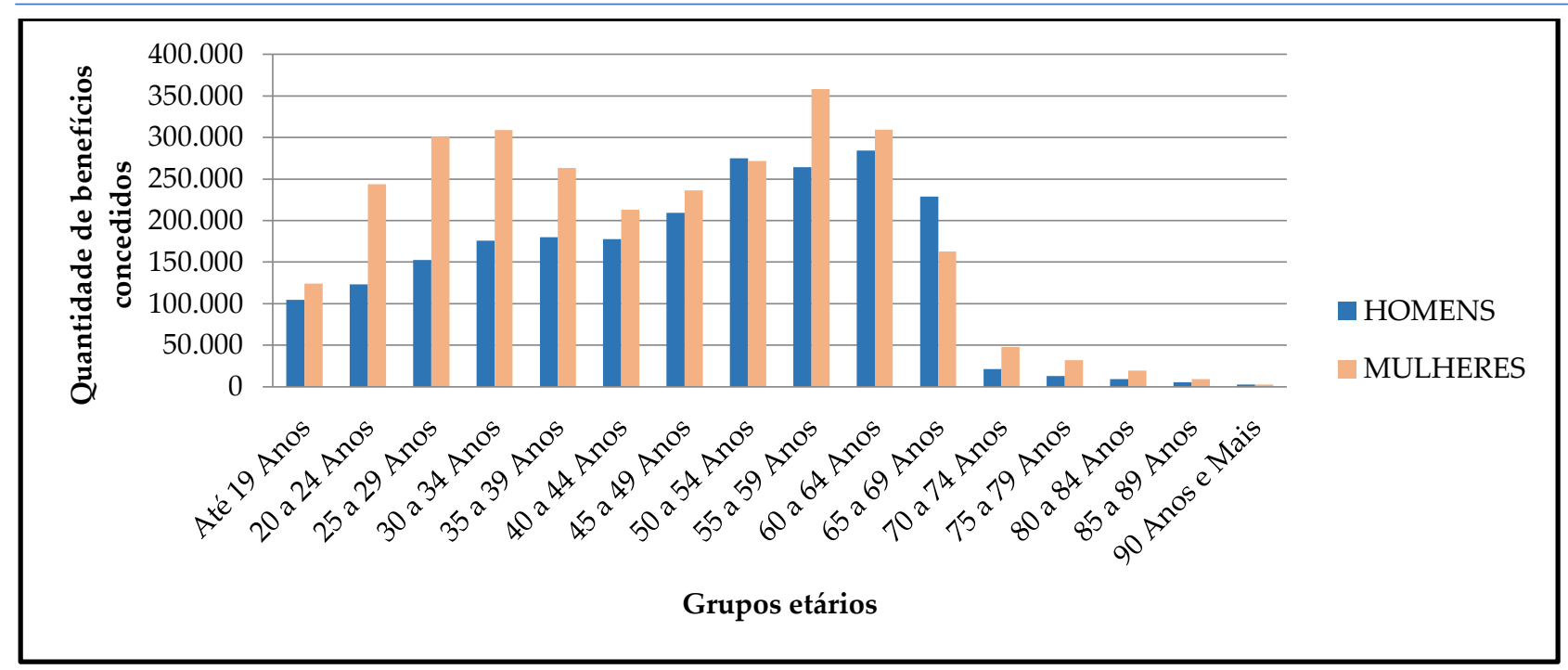

Fonte: Adaptado de Aeps InfoLogo, 2016.

Assim, após a análise das taxas específicas, foi calculado o quociente entre o somatório dos gastos previdenciários com benefícios concedidos por grupos etários em 2016 e a população total do Brasil no mesmo ano, obtendo-se a taxa bruta de gastos previdenciários (TBGP) de 32,26, ou seja, o consumo de gastos previdenciários é de $\mathrm{R} \$ 32,26$ por habitante. O mesmo cálculo foi feito por sexos, resultando em $R \$ 32,02$ para os homens e de $R \$ 32,49$ para as mulheres, evidenciando que as mulheres consomem mais dos gastos previdenciários do que os homens em termos per capita.

O próximo passo foi aplicar a estrutura etária da população da Itália na população total do Brasil, considerando que a população não aumentou ou reduziu de volume, mas apenas alterou a estrutura etária, este ajuste foi elaborado para melhor avaliar os resultados obtidos dos gastos previdenciários estimados. Multiplicando, essa população em cada grupo etário com as taxas específicas de consumo resultou nos gastos previdenciários esperados (ou estimados) por grupos de idade. Fazendo o somatório desses resultados e dividindo pela população com a nova estrutura etária, gerou-se a taxa bruta de consumo padronizada de gastos previdenciários ( $\left.T B C_{\text {p.d. }}\right)$.

De forma análoga, os cálculos foram feitos também por sexo. Os resultados encontrados apresentam-se na Tabela 02, onde se pode observar que de fato os gastos previdenciários aumentarão em uma população mais envelhecida, passando de $\mathrm{R} \$ 32,02$ para $\mathrm{R} \$ 41,48$ em relação aos homens, um aumento em cerca de $30 \%$, entre as mulheres passou de $R \$ 32,49$ para $R \$ 37,36$, uma variação de $15 \%$, e já em relação à população total foi uma mudança de $R \$ 32,26$ para $R \$ 39,27$, uma elevação de $22 \%$. Vale ressaltar que essas alterações foram decorrentes apenas do envelhecimento populacional.

A diferença entre os valores pode parecer pouca, mas se considerar que o volume da população aumentará até chegar à última fase da transição demográfica, alterando assim as taxas específicas de consumo, esses $\mathrm{R} \$ 39,27$ por habitante pode apresentar-se como um aumento considerável nas contas previdenciárias.

TABELA 02- Resultados da aplicação da técnica da padronização direta sobre os gastos previdenciários.

\begin{tabular}{|c|c|c|}
\hline População & TBGP (em reais) & $T B C_{p . d .}$ (em reais) \\
\hline Homens & 32,02 & 41,48 \\
\hline Mulheres & 32,49 & 37,36 \\
\hline Total & 32,26 & 39,27 \\
\hline
\end{tabular}

Fonte: Adaptado de Aeps InfoLogo, 2016.

\section{CONSIDERAÇÕES FINAIS}


No presente trabalho foi discutida a transição demográfica, desde seu início, com a queda das taxas de mortalidade e fecundidade, até sua consequência na estrutura etária da população com o aumento da proporção da população idosa em relação à jovem, evidenciando a velocidade deste processo no Brasil em relação a outros países.

Uma das principais políticas públicas afetadas pelo envelhecimento populacional é o RGPS, como se baseia no regime financeiro de repartição simples, e, portanto, necessita da relação intergeracional entre contribuintes e beneficiários para se sustentar. Espera-se que a população brasileira, por volta de 2050 já vivenciará uma estrutura etária envelhecida, acarretando um aumento dos aposentados e uma diminuição dos contribuintes da previdência social. O discurso sobre este cenário que aguarda o Brasil vem sendo discutido de forma mais evidente devido ao déficit previdenciário existente, que a cada ano se mostra cada vez mais crescente, e por isso há a pressão de haver uma reforma previdenciária para se adaptar a esta população. É sabido que a previdência social já passou por duas principais reformas, com o intuito de minimizar e até acabar com o déficit, no entanto, este ainda se mostra em ascendência.

Através das informações populacionais coletadas no Banco Mundial referentes as populações do Brasil e da Itália, e dos gastos previdenciários com benefícios concedidos de 2016, foi possível estimar o nível de gastos previdenciários que o Brasil possivelmente vivenciará em uma população envelhecida. Os resultados foram que com uma população jovem (brasileira em 2016) os gastos com benefícios concedidos eram de $\mathrm{R} \$ 32,26$ por habitante e que ao mudar a estrutura etária (italiana em 2016) passou para $R \$ 39,27$ por habitante. Como para tal estudo não foi considerado o aumento no volume da população e apenas uma mudança na estrutura etária, acredita-se que quando o Brasil estiver vivenciando uma estrutura etária mais envelhecida o aumento nos gastos seja mais expressivo, devido ao crescimento da população idosa.

Com base nestes mesmos dados foi calculada a intensidade do consumo dos gastos previdenciários por grupos etários e sexo. Onde foi verificado que ao contrário do senso popular em pensar que os maiores dispêndios com benefícios concedidos ocorrem para os idosos, a maior intensidade dos gastos previdenciários ocorre de fato em relação aos adultos, e que apesar de haver um diferencial ente os sexos durante toda a distribuição etária, ambos tendem ao mesmo comportamento. Portanto, os custos com benefícios para a população em idade ativa apresentam mais representativos do que comparado aos dispêndios referente ás aposentadorias, seja pelo valor ou pela quantidade, devido á concessão dos auxílios assegurados pela previdência social. No entanto, ao final da transição demográfica espera-se que as despesas previdenciárias aumentem, pois apesar da PIA continuar representando uma maior parte entre os beneficiários, a quantidade de idosos aumentará consideravelmente.

Outro ponto ressaltado na análise do consumo dos benefícios previdenciários foi que apesar das mulheres se mostrarem como maiores beneficiárias em termos de quantidade (Gráfico 11), os homens são quem recebem benefícios mais altos. Esta característica pode ser explicada pelo fato das mulheres receberem, em média, aposentadorias menores do que os homens, devido ao seu tratamento diferenciado no mercado de trabalho (Marri, Wajnman \& Andrade, 2011). Em 2016, através da análise dos dados coletados no Aeps InfoLogo, em média cada homem recebia $\mathrm{R} \$ 1.467,47$ de benefícios previdenciários, enquanto que as mulheres recebiam $\mathrm{R} \$ 1.181,11$, afirmando portanto a diferenciação por sexo sobre os valores dos benefícios.

Dado que no estudo foram estabelecidas algumas restrições, recomenda-se para trabalhos futuros a projeção dos gastos previdenciários para 2050, e a análise da equidade entre os sexos na previdência social organizada pelo regime geral, dada as diferenças observadas no tratamento entre os homens e as mulheres no mercado de trabalho.

À guisa de conclusão, considerando que o envelhecimento populacional é um processo consolidado e provavelmente irreversível, a necessidade de ajustes e reformas na previdência soci- 
al devem sempre estar no topo das agendas dos agentes públicos, balizados pelo comportamento das inúmeras variáveis que interferem no equilíbrio financeiro e atuarial do sistema, com destaque para a mudança na estrutura etária da população. Destaca-se, por fim, que nenhuma reforma trará solução definitiva e perpétua para o sistema previdenciário brasileiro, sendo imperativa a contínua avaliação de revisão do RGPS, baseada em ampla discussão com todos os agentes da sociedade envolvidos, de modo que se garanta sustentabilidade para essa importante ferramenta de seguridade e bem-estar social.

\section{REFERÊNCIAS}

Alves, J. E. D, Vasconcelos, D. S., \& Carvalho, A. A. (2010) . Estrutura etária, bônus demográfico e população economicamente ativa no Brasil: cenários de longo prazo e suas implicações para o mercado de trabalho. Texto para discussão, no 10. CEPAL - IPEA.

Amaro, M. N. (2011). Terceira reforma previdenciária: Até quando esperar? . Texto para discussão,

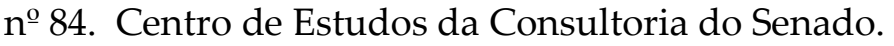

Anuário Estatístico Da Previdência Social (2017)- Aeps InfoLogo. Disponível em:< http://www3.dataprev.gov.br/infologo/ >. Acesso em: 05 de Março de 2017.

Banco Mundial. Disponível em: < http://data.worldbank.org/ >. Acesso em: 18 de Outubro de 2018.

Barros, C. (2012). O modelo de proteção social brasileiro. Disponível em: < https://jus.com.br/artigos/21775/o-modelo-de-protecao-social-brasileiro >. Acesso em: 13 de Outubro de 2017.

Beltrão, K.I., Leme, F.P., Mendonça, J.L., \& Sugahara, S. (2004). Análise Da Estrutura Da Previdência Privada Brasileira: Evolução Do Aparato Legal. Texto para discussão, no ${ }^{-1043}$. CEPAL IPEA.

Bloom, D. E., Canning, D., \& Sevilla, J. (2003). The Demographic Dividend: A New Perspective on the Economic Consequences of Population Change. Santa Mônica: Rand Corporation. p. 126.

Brasil, Constituição (1988). Constituição da República Federativa do Brasil: texto constitucional promulgado em 5 de outubro de 1988, com as alterações adotadas pelas Emendas constitucionais nºs 1/1992 a 92,2016, pelo Decreto legislativo no 186/2008 e pelas Emendas constitucionais de revisão n⿳os 1 a 6/1994.-49.ed.-Brasília:Câmara dos Deputados, Edições Câmara, 2016.

Brasil. (2002). Ministério da Previdência e Assistência Social (MPAS). Livro Branco da Previdência Social. Brasília: MPAS/GM, dez.

Brito, F. (2007).A transição demográfica no Brasil: as possibilidades e os desafios para a economia e a sociedade. Texto para discussão, nº 318 - CEDEPLAR, Belo Horizonte/MG.

Bruno, M. A.P. (2007). “Transição demográfica e regime de regime de acumulação financeirizado no Brasil: "bônus" ou "ônus" para a previdência social?". In: Carta Social e Do Trabalho no 
07. Previdência Social: Como incluir os excluídos?. Centro de estudos sindicais e de economia do trabalho- Cesit. p.106-122.

Caetano, M. A. R., Rangel, L. A., Pereira, E.S., Ansiliero, G., Paiva, L.H., \& Costanzi, R.N. (2016). O fim do fator previdenciário e a introdução da idade mínima: questões para a previdência social no Brasil. Brasília: Ipea. (Texto para Discussão, n. 2230). Disponível em: $<$ https://goo.gl/1dVFF1>

Carvalho, J. A., \& Wong, L. L. R. (2006). O rápido processo de envelhecimento populacional do Brasil: sérios desafios para as políticas públicas. Revista Brasileira de Estudos Populacionais, São Paulo, 23 (1), p.5-26, jan/jun.

Carvalho, J.A.M., \& Wong, L.L.R. (2008). A transição da estrutura etária da população brasileira na primeira metade do século XXI. Cadernos de Saúde Pública. Rio de Janeiro: - 24 (3), p. 597605, mar. Disponível em: <http://ref.scielo.org/57xcwc>, Acesso em: 18 de Agosto de 2018.

Carvalho, J. A. M., Sawyer, D. O. , \& Rodrigues, R. N. (1998). Introdução a alguns conceitos básicos e medidas em demografia. Belo Horizonte: Série Textos Didáticos. n.1, 2ª ed., ABEP.

Chade, J. (2010). Europa envelhece e reforma previdência: Impacto do envelhecimento da população, segundo a OCDE, é bem maior do que a crise financeira para as contas do continente. Disponível em: < http://economia.estadao.com.br/noticias/geral,europa-envelhece-e-reformaprevidencia-imp-,628961 >. Acesso em: 17 de Outubro de 2016.

Costanzi, R. N. (2016) Estrutura demográfica e despesa com previdência: comparação do Brasil com o cenário internacional. Informações Fipe, n. 423, p. 11-16. Disponível em: $<$ https://goo.gl/Kay3ut>.

Costanzi, R. N., \& Ansiliero, G. (2017). Impacto fiscal da demografia na previdência social. Rio de Janeiro: Ipea. (Texto para Discussão, n. 2291). Disponível em: <https://goo.gl/oTWdgq>

Emenda Constitucional no 20, de 15 de dezembro de 19998. Disponível em:< http://www.planalto.gov.br/ccivil_03/constituicao/emendas/emc/emc20.htm>. Acesso em: 04 de Setembro de 2019.

Emenda Constitucional no 41, de 19 de dezembro de 2003. Disponível em:< http://www.planalto.gov.br/ccivil_03/constituicao/Emendas/Emc/emc41.htm>. Acesso em: 04 de Setembro de 2019.

Emenda Constitucional $\mathrm{n}^{\mathrm{o}}$ 47, de 05 de julho de 2005. Disponível em:< http://www.planalto.gov.br/ccivil_03/constituicao/Emendas/Emc/emc47.htm >. Acesso em: 04 de Setembro de 2019.

Gentil, D. L. (2006). A Política Fiscal e a Falsa Crise da Seguridade Social Brasileira: Análise financeira do período 1990-2005. p. 358. Tese (Doutorado) - Curso de Economia, Universidade Federal do Rio de Janeiro, Rio de Janeiro, 2006.

Giambiagi, F., \& Tafner, P. (2010). Demografia a ameaça invisível- O dilema previdenciário que o Brasil se recusa a encarar. 1를. Ed. Rio de Janeiro: Editora Elsevier, p. 198. 
Goiás. (2013). Dinâmica Populacional de Goiás: Características e discrepâncias do bônus demográfico em Goiás. Goiânia: Instituto Mauro Borges de Estatísticas e Estudos Socioeconômicos/Segplan. Disponível em: < http://www.imb.go.gov.br/files/docs/publicacoes/estudos/2013/dinamica-populacionalcaracteristicas-e-discrepancias-do-bonus-demografico-em-goias.pdf >. Acesso em: 02 de Setembro de 2019.

Instituto Brasileiro De Geografia E Estatística (2016)- IBGE. Disponível em: < http://www.ibge.gov.br >. Acesso em: 29 de Maio de 2016.

Instituto Brasileiro De Geografia E Estatística - IBGE. Projeções da população: Brasil e unidades da federação: revisão 2018. Coordenação de População e Indicadores Sociais. - 2. ed. - Rio de Janeiro, 2018.

Kertzman, I., \& Martinez, L. (2014). Guia Prático da Previdência Social. 5. ed. São Paulo: Saraiva. p. 244.

Lei $\mathrm{n}^{\mathrm{o}}$ 9.717, de 27 de novembro de 1998. Brasília, 1998. Disponível em: < http://www.planalto.gov.br/ccivil_03/Leis/L9717.htm >. Acesso em: 15 de Novembro de 2016.

Lei $\mathrm{n}^{\mathrm{o}}$ 9.816, de 23 de agosto de 1999. Brasília, 1999. Disponível em:< https://www2.camara.leg.br/legin/fed/lei/1999/lei-9816-23-agosto-1999-372259-

publicacaooriginal-1-pl.html >. Acesso em: 04 de Setembro de 2019.

Lei $\mathrm{n}^{\mathrm{o}}$ 13.134, de 16 de junho de 2015. Brasília, 2015. Disponível em: < http://www.planalto.gov.br/ccivil_03/_Ato2015-2018/2015/Lei/L13134.htm >. Acesso em: 15 de Novembro de 2016.

Lei $\mathrm{n}^{\mathrm{o}}$ 13.135, de 17 de junho de 2015. Disponível em: < http://www.planalto.gov.br/ccivil_03/_ato2015-2018/2015/lei/113135.htm >. Acesso em: 15 de Novembro de 2016.

Lei $\mathrm{n}^{\mathrm{o}}$ 13.183, de 04 de novembro de 2015. Brasília, 2015. Disponível em: < http://www.planalto.gov.br/ccivil_03/_Ato2015-2018/2015/Lei/L13183.htm >. Acesso em: 15 de Novembro de 2016.

Lima, D. V. (2013). A dinâmica demográfica e a sustentabilidade do modelo de financiamento do regime geral de previdência social. p. 147. Tese (Doutorado) - Curso de Programa Multiinstitucional e Inter-regional de Pós-graduação em Ciências Contábeis, Universidade de Brasília; Universidade Federal da Paraíba; Universidade Federal do Rio Grande do Norte, Distrito Federal, 2013.

Lima, S. C., \& Diniz, J.A. (2016). Contabilidade Pública: Análise Financeira Governamental. São Paulo: Atlas. p. 576.

Lobato, L. V. C., Costa, A. M., \& Rizzotto, M. L. F. (2019). Reforma da previdência: o golpe fatal na seguridade social brasileira. Revista Saúde em Debate, Rio de Janeiro, 43 (120), p.5-14, jan/mar. 
Marri, I, G., Wajnman , S., \& Andrade , M. V. (2011). Reforma da Previdência Social: simulações e impactos sobre os diferenciais de sexo. Revista Brasileira de Estudos de População, Rio de Janeiro, 28(1), p.37-56, jan/jun.

Matos, P. R. F., Melo, F. S. P., \& Simonassi, A. G. (2013). Análise de Solvência do Regime Geral da Previdência Social no Brasil. Estudos Econômicos, São Paulo, 43(2), p.301-333, abril/jun.

Paz, A., Pinto, C. C. (2010). Regimes Financeiros e Métodos de Financiamento para Entidades Fechadas de Previdência Complementar. In: Comissão Nacional de Atuária. Coletânea de Artigos sobre Tábuas de Mortalidade, Taxas de Juros e Métodos de Financiamento. Superintendência Nacional de Previdência Complementar - Previc. MPS. p.279-293.

Rocha, R. R., \& Caetano, M. A. (2008). O Sistema Previdenciário Brasileiro: Uma Avaliação de Desempenho Comparada. Texto para discussão, nํㅜㄹ 1331. CEPAL - IPEA.

Salvati, L., Carlucci, M., Serra, P., \& Zambon, I. (2019). Demographic Transitions and Socioeconomic Development in Italy, 1862-2009: A Brief Overview. Sustainability, [s.l.], 11(1), p.242-254, jan. MDPI AG. http://dx.doi.org/10.3390/su11010242.

Secretaria Da Previdência. (2019). Ministério Da Economia. Disponível em:< http://www.previdencia.gov.br/ >. Acesso em: 01 de Fevereiro de 2019.

Silva, D. G. P. (2013). Benefícios Previdenciários no RPPS. Disponível em: < http://www.sbcprev.saobernardo.sp.gov.br/atualiza/docs/delubio.pdf >. Acesso em: 13 de Outubro de 2016.

Souza, M. E. A.(2011). Déficit previdenciário: fato ou mito? Cognitio Juris, João Pessoa, Ano I, Número 3. Disponível em < http://www.cognitiojuris.com/artigos/03/05.html >. Acesso em: 15 de Novembro de 2016.

Tafner, P.(2012). Desafios e reformas da previdência social brasileira. Revista Usp, São Paulo, (93), p.137-156, mar/abr/mai.

Tafner, P., Botelho, C., \& Erbisti, R.(2014). Transição Demográfica e o Impacto Fiscal

Na Previdência Brasileira. In: Novo regime demográfico: uma nova relação entre população e desenvolvimento ?. IPEA. p. 539-570

Vasconcelos, A. M. N., \& Gomes, M. M. F. (2012). Transição demográfica: a experiência brasileira. Epidemiologia e Serviços de Saúde, Brasília, 21 (4), p.539-548, out/dez. 